ఠ

\title{
Forodesine in the treatment of relapsed/refractory peripheral T-cell lymphoma: an evidence-based review
}

This article was published in the following Dove Press journal:

OncoTargets and Therapy

\author{
Shinichi Makita' \\ Akiko Miyagi Maeshima² \\ Dai Maruyama' \\ Koji Izutsu' \\ Kensei Tobinai' \\ 'Department of Hematology, \\ ${ }^{2}$ Department of Pathology, National \\ Cancer Center Hospital, Chuo-ku, \\ Tokyo, Japan
}

Correspondence: Shinichi Makita Department of Hematology, National Cancer Center Hospital, 5-I-I Tsukiji, Chuo-ku, Tokyo 104-0045, Japan

$\mathrm{Tel}+8$ I 3354225 I I

Fax +8I 335423815

Email smakita@ncc.go.jp

\begin{abstract}
T-cell lymphoma is a rare hematologic malignancy with an incidence rate between $10 \%$ and $20 \%$ of that of non-Hodgkin lymphomas. Patients with peripheral T-cell lymphoma (PTCL) generally have a poor prognosis when treated with cyclophosphamide, doxorubicin, vincristine, and prednisolone (CHOP)/CHOP-like chemotherapy; once relapse occurs, it is mostly regarded as an incurable disease. To overcome the chemorefractoriness of PTCL, several novel agents have been developed. Since the first approval of pralatrexate, a dihydrofolate reductase inhibitor, for relapsed/ refractory PTCL by the US Food and Drug Administration, several new agents, such as romidepsin (histone deacetylase inhibitor), brentuximab vedotin (antibody-drug conjugate targeting CD30), chidamide (histone deacetylase inhibitor), and mogamulizumab (anti-CC chemokine receptor 4 monoclonal antibody), have been approved as a therapeutic option for relapsed/refractory PTCL in several countries, including the US, Europe, China, and Japan. Forodesine is a novel, potent purine nucleoside phosphorylase inhibitor that is effective against T-cell malignancies. Although the clinical development of forodesine was discontinued in the US and Europe, a multicenter Phase I/II study of oral forodesine for relapsed PTCL was recently completed in Japan. The overall response rate was $24 \%$ ( 10 of 41 patients), which included four patients with complete response. In general, the toxicity of forodesine is manageable. As the study met the primary end point, forodesine was approved for the treatment of relapsed/refractory PTCL in Japan in March 2017, which was the first approval of forodesine in the world. As forodesine is an oral formulation, it is more convenient than other novel intravenous agents approved for PTCL. However, it is necessary to appropriately manage opportunistic infections and secondary lymphomas possibly associated with long-lasting lymphocytopenia caused by forodesine. In this manuscript, we have summarized the currently available evidence for forodesine and discussed the clinical implications for PTCL treatment.
\end{abstract}

Keywords: forodesine, PTCL, T-cell lymphoma, new agents, lymphoma, non-Hodgkin lymphoma, PNP, purine nucleoside phosphorylase

\section{Introduction}

T-cell/natural killer (NK)-cell lymphoma is a rare lymphoid neoplasm and its incidence rate is $10 \%-20 \%$ of that of non-Hodgkin lymphomas (NHLs). ${ }^{1,2}$ T/NK-cell lymphoma is divided into several histologic subtypes based on the WHO classification, ${ }^{1}$ including peripheral T-cell lymphoma, not otherwise specified (PTCL-NOS); angioimmunoblastic T-cell lymphoma (AITL); nodal peripheral T-cell lymphoma with T follicular helper (TFH) phenotype; anaplastic lymphoma kinase (ALK)-positive anaplastic large cell lymphoma (ALCL); ALK-negative ALCL, adult T-cell leukemia-lymphoma (ATL); and extranodal NK/T-cell lymphoma, nasal type (ENKL). Among these, ATL and ENKL are considered distinct disease entities associated with specific viral 
infections, and the recommended first-line treatment strategies are different from those of other T-cell lymphomas. ${ }^{3,4}$ Therefore, this review focuses on T-cell lymphomas except for ATL and ENKL.

Systemic T-cell lymphomas (so-called, peripheral T-cell lymphomas [PTCLs]) are difficult to treat and have unfavorable prognoses, mainly because most PTCLs are refractory to conventional cytotoxic chemotherapies. Except for ALKpositive ALCL with lower risk by International Prognostic Index, which has favorable prognosis, ${ }^{2}$ patients with PTCLs generally have poor prognosis when treated with cyclophosphamide, doxorubicin, vincristine, and prednisolone (CHOP)/CHOP-like chemotherapy; the 5-year progressionfree survival (PFS) rate is $31 \%-36 \%$ and the 5 -year overall survival (OS) rate is $48 \%-55 \%{ }^{5,6}$ Once relapse occurs, the disease is regarded as mostly incurable. ${ }^{7}$

To overcome the chemorefractoriness of PTCLs, several agents have been developed. Since the approval of pralatrexate, a dihydrofolate reductase inhibitor, for relapsed/ refractory PTCL by the US Food and Drug Administration (FDA), ${ }^{8}$ several new agents, such as romidepsin (histone deacetylase inhibitor), ${ }^{9-12}$ brentuximab vedotin (antibodydrug conjugate targeting CD30), ${ }^{13-15}$ chidamide (histone deacetylase inhibitor), ${ }^{16}$ and mogamulizumab (anti-CC chemokine receptor 4 monoclonal antibody), ${ }^{17-20}$ have been approved as a therapeutic option for relapsed/refractory PTCL in several countries, including the US, Europe, China, and Japan. The results of the key trial of these agents are summarized in Table 1, and their schematic mechanisms of actions are shown in Figure 1..$^{8-11,13-16,18-22}$
Recently, forodesine (formerly known as BCX-1777), a novel purine nucleoside phosphorylase (PNP) inhibitor, was approved for the treatment of relapsed/refractory PTCL in Japan; this was the first approval of forodesine in the world. In this manuscript, we have summarized the currently available evidence for forodesine and discussed its clinical implications for the current and future treatment of PTCLs.

\section{Role of PNP and effects of PNP inhibition}

The enzyme PNP participates in the purine salvage pathway and is present at high levels in lymphoid tissues. It catalyzes the phosphorolysis of $2^{\prime}$-deoxyguanosine (dGuo) to a guanine base and 2'-deoxyribose-1-phosphate. ${ }^{23}$ PNP has been proposed as one of the most promising therapeutic targets for T-cell malignancies, because children born with PNP deficiency have severely reduced T-cell counts, with relatively normal B-cell immunity. ${ }^{24}$ Preclinical studies revealed that PNP deficiency increased the dGuo concentration in plasma and in T cells. ${ }^{25}$ An increased concentration of dGuo results in deoxyguanosine triphosphate (dGTP) accumulation (Figure 1). This causes an imbalance of the deoxynucleotide pool, which reduces the activity of ribonucleotide reductase and leads to T-cell apoptosis. ${ }^{26}$ Based on this hypothesis, the intravenous infusion therapy of dGuo was evaluated; however, this strategy was unable to achieve higher dGuo plasma levels because the half-life $\left(t_{1 / 2}\right)$ of plasma dGuo is only $12 \mathrm{~s}$. Therefore, the pharmacological inhibition of PNP was thought to be a more suitable method to achieve T-cell suppression.

Table I Clinical efficacy of selected novel agents for relapsed/refractory T-cell lymphoma

\begin{tabular}{|c|c|c|c|c|c|c|c|}
\hline Agents & Disease subtype & No of Pts & ORR (\%) & CR rate $(\%)$ & $\begin{array}{l}\text { Median PFS } \\
\text { (months) }\end{array}$ & $\begin{array}{l}\text { Median DoR } \\
\text { (months) }\end{array}$ & References \\
\hline Brentuximab & $\mathrm{ALCL}$ & 58 & 86 & 57 & 20 & 12.6 & Pro et al $(2012)^{13}$ \\
\hline \multirow[t]{2}{*}{ vedotin } & CD30-positive PTCL & 34 & 41 & 24 & 2.6 & 6.7 & Horowitz et al $(2014)^{14}$ \\
\hline & CD30-positive CTCL & 64 & 67 & 16 & 16.7 & 16.7 & Prince et al $(2017)^{15}$ \\
\hline Vorinostat & $\mathrm{CTCL}$ & 74 & 30 & NA & 4.9 & 5.6 & Mann et al $(2007)^{21}$ \\
\hline \multirow[t]{3}{*}{ Romidepsin } & CTCL & 71 & 34 & 5 & NA & 13.7 & Piekarz et al (2009)9 \\
\hline & CTCL & 96 & 38 & I & 8 & 15 & Whittaker et al $(2010)^{10}$ \\
\hline & PTCL & 130 & 25 & 15 & 4 & 28 & Coiffier et al $(2014)^{\prime \prime}$ \\
\hline Belinostat & PTCL & 120 & 26 & 11 & 1.6 & 13.6 & O'Connor et al $(2015)^{22}$ \\
\hline Chidamide & PTCL & 79 & 28 & 14 & 2.1 & 9.9 & Shi et al $(2015)^{16}$ \\
\hline Pralatrexate & PTCL & $\mathrm{III}$ & 29 & 11 & 3.5 & 10.1 & O'Connor et al $(20 \mathrm{II})^{8}$ \\
\hline \multirow[t]{3}{*}{ Mogamulizumab } & CCR4-positive PTCL/CTCL & 37 & 35 & 14 & 3 & NA & Ogura et al $(2014)^{18}$ \\
\hline & CCR4-positive PTCL & 35 & 11 & 3 & 2 & 2.8 & Zinzani et al $(2016)^{19}$ \\
\hline & CTCL & 38 & 37 & 7.9 & 11.4 & 10.4 & Duvic et al $(2015)^{20}$ \\
\hline \multirow[t]{2}{*}{ Forodesine } & $\mathrm{PTCL}^{\mathrm{a}}$ & 41 & 24 & 10 & 1.9 & 10.4 & Shibayama et al $(2017)^{42}$ \\
\hline & CTCL & 101 & 11 & 0 & NA & 6.4 & Dummer et al $(2014)^{39}$ \\
\hline
\end{tabular}

Note: aRefractory patients were not included in these studies.

Abbreviations: ALCL, anaplastic large cell lymphoma; CCR4, CC chemokine receptor 4; CR, complete response; CTCL, cutaneous T-cell lymphoma; DoR, duration of response; NA, not available; ORR, overall response rate; PTCL, peripheral T-cell lymphoma; Pts, patients; PFS, progression-free survival. 


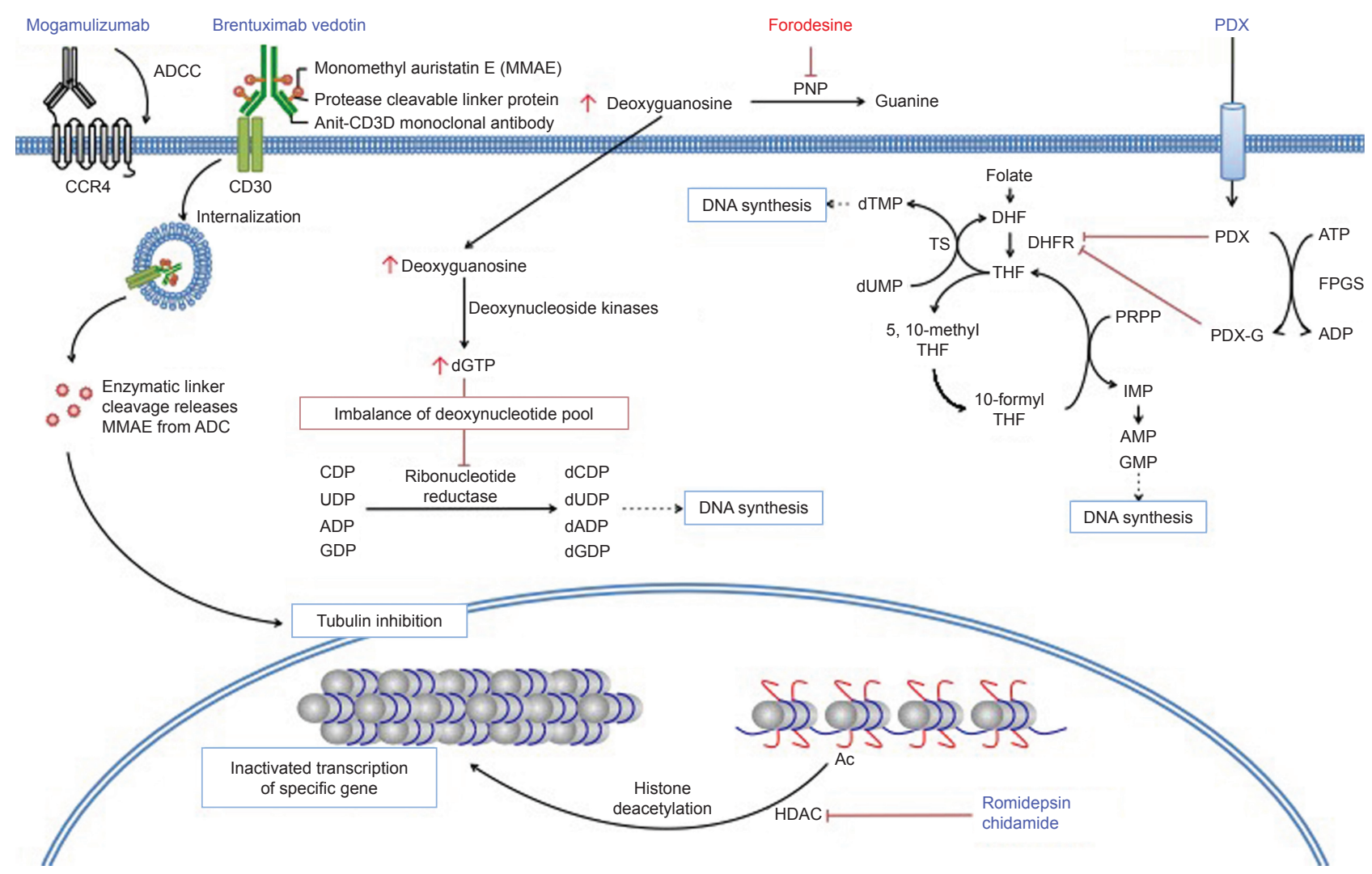

Figure I Selected novel agents for PTCL.

Abbreviations: ADC, antibody-drug conjugate; ADCC, antibody-dependent cell-mediated cytotoxicity; CCR4, CC chemokine receptor 4; DHF, dihydrofolate; DHFR, dehydrofolate reductase; FPGS, folylpolyglutamate synthase; HDAC, histone deacetylase; IMP, inosine monophosphate; PDX, pralatrexate; PDX-G, polyglutamylated pralatrexate; PNP, purine nucleoside phosphorylase; PRPP, 5-phosphoribosyl-I-pyrophosphate; PTCL, peripheral T-cell lymphoma; THF, tetrahydrofolate; TS, thymidylate synthase.

Several compounds that inhibit PNP have been developed, but most did not reach clinical trials because of low efficacy associated with a low inhibitory potency against PNP. ${ }^{27,28}$ Peldesine (BCX-34) is a relatively potent PNP inhibitor $\left(\mathrm{IC}_{50}[50 \%\right.$ inhibitory concentration $\left.]=30 \mathrm{nM}\right) .^{29}$ The compound was tested in patients with cutaneous T-cell lymphoma (CTCL) and psoriasis, which is a T-cell-mediated skin disorder. However, limited efficacy was observed, partly because of the rapid release of peldesine from PNP and the inability of peldesine to sufficiently inhibit PNP and elevate plasma dGuo to the level necessary for T-cell suppression. Furthermore, the pharmacokinetic (PK)/pharmacodynamic (PD) properties revealed that the oral dosing of peldesine could not achieve a sufficient increase in dGuo to suppress T cells. ${ }^{30,31}$

Forodesine is a novel, potent PNP inhibitor $\left(\mathrm{IC}_{50}=\right.$ $0.48-1.57 \mathrm{nM}) .^{32,33}$ It is a transition state analog of PNP and is between 100- and 1,000-fold more potent than previous PNP inhibitors. ${ }^{34,35}$ Although forodesine is also a member of purine analogs, it contains nitrogen in the ring of D-ribofuranose and C-glycosidic bond (Figure 2). In contrast to other purine nucleoside analogs, forodesine does not act via direct incorporation into DNA but displays a highly selective PNP inhibition because of such a unique structure.

Based on the promising preclinical results, clinical trials of forodesine for PTCL, CTCL, and T-cell leukemia have been conducted.

\section{Clinical trials of forodesine Early clinical trials for T-cell leukemia}

Gandhi et al conducted the first-in-human Phase I study of forodesine in patients with relapsed/refractory T-cell

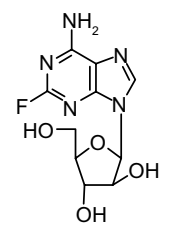

Fludarabine

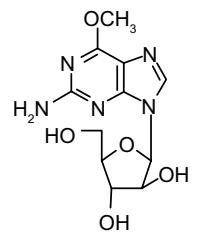

Nelarabine

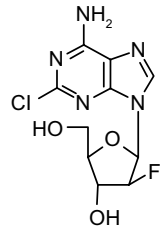

Clofarabine

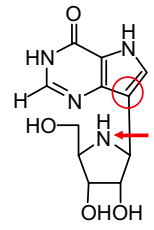

Forodesine
Figure 2 Structures of purine nucleoside analogs.

Notes: Forodesine is a member of purine nucleoside analogs. Unlike the other purine nucleoside analogs, forodesine contains nitrogen in the ring of $D$-ribofuranose (red arrow) and C-glycosidic bond (red ring). 
malignancies. ${ }^{36}$ In this study, forodesine was administered intravenously via a 30-minute infusion, at a dose level of $40 \mathrm{mg} / \mathrm{m}^{2}$. The dosing pattern comprised a single administration on day 1 , and then two administrations at 12-hour intervals on days 2-5; a 21- to 28-day cycle was used. The starting dose and schedule of forodesine were determined based on data from preclinical studies in primates. Based on the activity and toxicity, the suggested maximum daily exposure in primates was $20 \mathrm{mg} / \mathrm{kg} / \mathrm{day}$, which was considered to be the equivalent of $800 \mathrm{mg} / \mathrm{m}^{2} /$ day.

Five patients with relapsed/refractory T-cell malignancies (T-acute lymphoblastic leukemia [T-ALL], n=2; $\mathrm{T}$-prolymphocytic leukemia, $\mathrm{n}=3$ ) received an intravenous infusion of forodesine. In all patients, a sufficient increase of plasma dGuo was observed. From a cellular pharmacology perspective, four out of five patients achieved a 10 - to 20 -fold increase in the intracellular dGTP level within $24 \mathrm{~h}$ of the first infusion. Although no objective responses were observed, the four patients with increased intracellular dGTP level had stable disease, whereas the remaining patients had progressive disease. Based on these results, the antitumor activity of forodesine was thought to be correlated with intracellular accumulation of dGTP. After the first five patients were enrolled, a review of the clinical and pharmacological data suggested that an alternative dosing schedule of forodesine should be considered; therefore, enrollment in this study was stopped. The PK investigations of forodesine in plasma showed that 4-8 $\mu \mathrm{M}$ concentration was achieved from a $40 \mathrm{mg} / \mathrm{m}^{2}$ starting dose, which was therefore sufficient to achieve effective inhibition. However, the peak level of forodesine (median $5.4 \mu \mathrm{M}$ ) and the long $\mathrm{t}_{1 / 2}$ (median $10 \mathrm{~h}$ ) suggested that once-daily dosing of $40 \mathrm{mg} / \mathrm{m}^{2}$ might be sufficient to provide and maintain adequate drug exposure for the inhibition of PNP.

Subsequently, Furman et al conducted a single-arm Phase II study of intravenous forodesine in patients with relapsed/refractory T-ALL. ${ }^{37}$ At the time of the interim analysis of this study, 34 patients were enrolled. The patients were intravenously administered forodesine $40 \mathrm{mg} / \mathrm{m}^{2} /$ day for 5 days each week (one cycle) for a total of six cycles. The dose was escalated to $90 \mathrm{mg} / \mathrm{m}^{2}$ in patients who did not respond after cycle 2 . The overall response rate (ORR) was $32 \%$ (11/34) with seven complete responses (CRs) and four partial responses (PRs). One patient who showed CR had continued to receive treatment for almost 1 year. Two patients with CR proceeded to hematopoietic stem cell transplantation after remission. In total, 18 patients received dose escalation to $90 \mathrm{mg} / \mathrm{m}^{2}$ after cycle 2 . However, none of these patients demonstrated an improved response after dose escalation.
Overall, intravenous forodesine was reasonably effective as a single agent for relapsed/refractory T-ALL, with manageable toxicity. However, the subsequent clinical data for forodesine in T-ALL have not been published.

\section{Clinical trials for CTCL}

Duvic et al conducted a Phase I/II trial of oral forodesine in patients with relapsed/refractory CTCL. ${ }^{38}$ This study enrolled patients with stage IB disease or higher, who were orally administered forodesine between 40 and $320 \mathrm{mg} / \mathrm{m}^{2}$, once daily for 4 weeks, to determine the maximum tolerated dose (MTD) and/or the optimal biological dose based on the PK and PNP inhibition, as evidenced by the elevation of plasma dGuo levels. However, MTD was not reached at any dose level. Based on the plateau of the area under the curve (AUC) versus dose plot at $80 \mathrm{mg} / \mathrm{m}^{2}$ and above, and the same observations for plasma dGuo versus dose, the once daily administration of $80 \mathrm{mg} / \mathrm{m}^{2}$ was judged as the optimal biological dose. In the 36 patients treated at this dose, the ORR with modified severity-weighted assessment tool was $39 \%$ (14/36), with a median duration of response of 127 days. The grade 3 or higher subjective adverse events related to the study treatment were vertigo, diarrhea, generalized edema, and pneumonia (one each). With regard to laboratory events, the grade 3 elevations of AST, ALT, bilirubin, and alkaline phosphatase was observed in one patient. Grade 3 or higher lymphocytopenia and low CD4 counts were observed in $71 \%$ and $31 \%$ of patients, respectively.

Subsequently, a multicenter Phase II study of forodesine for relapsed/refractory CTCL at a fixed dose of $200 \mathrm{mg} /$ day until disease progression was conducted. ${ }^{39}$ In total, 144 patients who had received three or more prior lines of systemic therapies were enrolled. Unlike the previous promising results, no CRs occurred and only 11\% (11 of 101 modified intent-to-treat population) of patients achieved PRs; 50\% $(51 / 101)$ had stable disease and 35\% (35/101) had progressive disease. Despite some durable responses (median of 261 days until progression), further clinical development for CTCL was halted.

\section{Clinical trials for PTCL}

In Japan, a Phase I study of oral forodesine in patients with relapsed/refractory mature $\mathrm{T} / \mathrm{NK}$-cell malignancy was conducted. ${ }^{40}$ In this study, three dose levels $(100,200$, and $300 \mathrm{mg}$, once daily) have been evaluated; 13 patients with relapsed/refractory PTCL and CTCL (five in the $100 \mathrm{mg}$ cohort; three in the $200 \mathrm{mg}$ cohort; five in the $300 \mathrm{mg}$ cohort) were enrolled. One patient with ALK-negative ALCL treated at $100 \mathrm{mg} /$ day achieved $\mathrm{CR}$, and PR was observed in two 
patients with CTCL treated at $200 \mathrm{mg} /$ day. With respect to the safety profile, the major adverse events of grade 3 or higher were lymphocytopenia $(8 / 13,62 \%)$, anemia $(2 / 13$, $15 \%)$, leukocytopenia $(1 / 13,8 \%)$, and pyrexia $(1 / 13,8 \%)$. No dose-limiting toxicity (DLT) was observed, even at the highest dose, and MTD was not determined. These data suggested that the MTD of forodesine might be much higher than that in this Phase I study. Based on the PK/PD data obtained from healthy volunteers (not published) in the Western countries, twice-daily (BID) administration of oral forodesine $300 \mathrm{mg}$ was equivalent to intravenous forodesine $40 \mathrm{mg} / \mathrm{m}^{2}$ once daily, which was the dose tested in T-ALL and CTCL. Furthermore, the PK profiles (AUC, $\mathrm{C}_{\max }$, and $\mathrm{C}_{\text {min }}$ ) of $300 \mathrm{mg}$ BID were significantly higher than that of $200 \mathrm{mg}$ BID, whereas the profiles of $300 \mathrm{mg}$ BID and $400 \mathrm{mg}$ BID were not. Therefore, the optimal dose of oral forodesine was expected to be $300 \mathrm{mg}$ BID.

Subsequently, a pivotal single-arm Phase I/II study of oral forodesine at a higher dose was conducted in patients with relapsed PTCL in Japan (NCT01776411). ${ }^{41,42}$ The primary end point of the Phase II portion was the ORR; the sample size of the Phase II portion was calculated to require at least 43 patients based on Simon's Minimax method.
The threshold response rate was $10 \%$, and the expected response rate was $25 \%$. The response was assessed by using computed tomography scanning and positron emission tomography scanning by an independent imaging review using IWC 2007 criteria. $^{43}$

In the Phase I portion, $3+3$ design was used and four patients received $300 \mathrm{mg}$ BID (600 mg/day). No DLTs were observed in the three evaluable patients. Therefore, the recommended Phase II dose was determined to be $300 \mathrm{mg}$ BID. In the Phase II portion, 44 patients received oral forodesine at $300 \mathrm{mg}$ BID. The results presented at the American Society of Hematology annual meeting in 2017 reported the ORR in 41 evaluable patients as $24 \%$ (10/41), which included four patients (10\%) with CRs. ${ }^{42}$ The median PFS and OS were 1.9 and 15.6 months, respectively, and the 2-year OS was $39 \%$. From a toxicity perspective, serious adverse events were reported in $46 \%$ of patients (22/48). The most common serious adverse events were pneumonia $(8 \%, 4 / 48)$, pyrexia $(6 \%, 3 / 48)$, Pneumocystis jirovecii pneumonia $(4 \%, 2 / 48)$, and anemia $(4 \%, 2 / 48)$. Grade 4 lymphocytopenia, observed in $81 \%$ of patients, was thought to be a major cause of opportunistic infections during the study treatment. Furthermore, five patients (three patients with AITL and
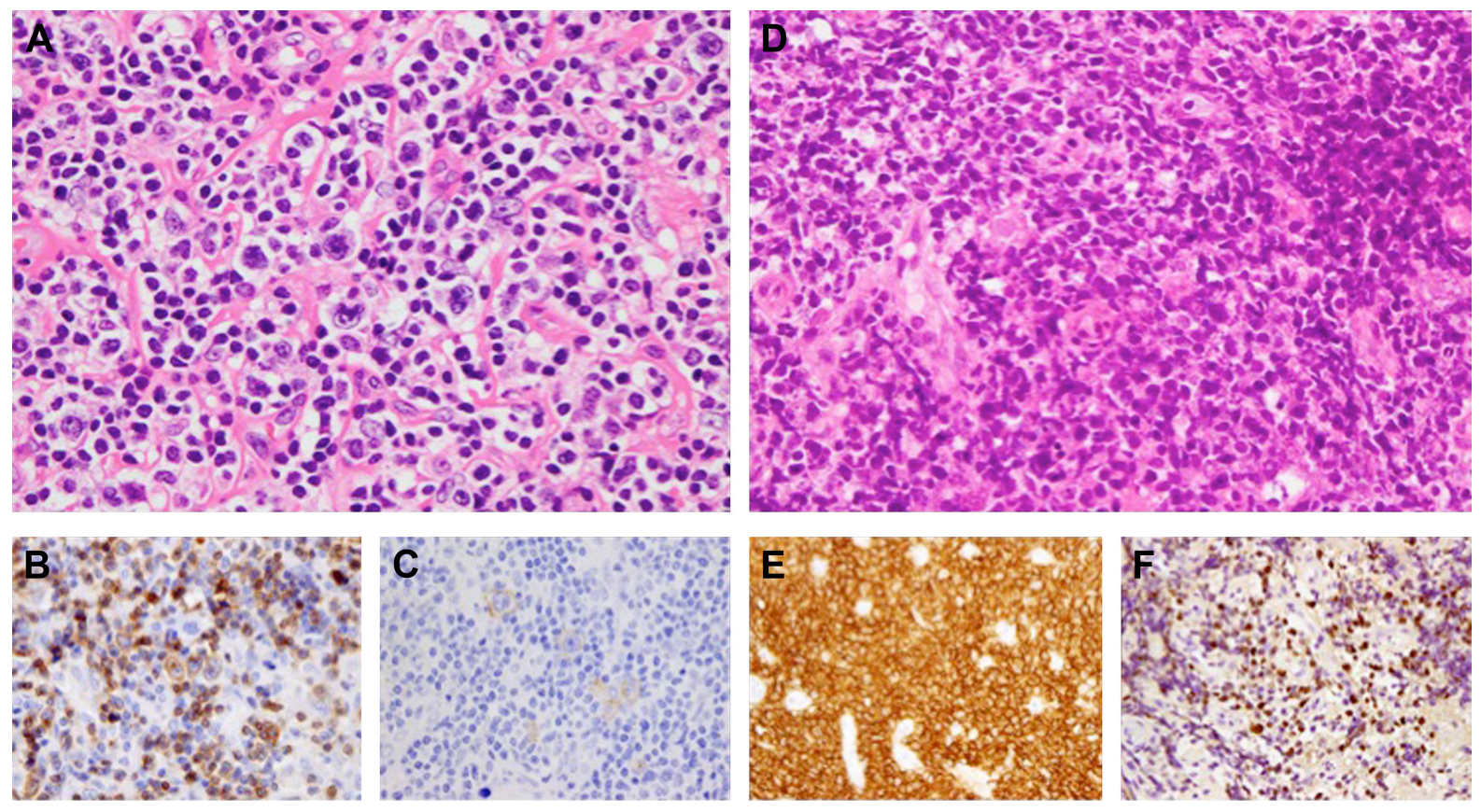

Figure 3 Epstein-Barr virus (EBV)-positive diffuse large B-cell lymphoma (DLBCL) developed during forodesine therapy.

Notes: A 68-year-old female was diagnosed with anaplastic lymphoma kinase (ALK)-negative anaplastic large cell lymphoma. Lymph node biopsy at the initial diagnosis revealed the disseminated presentation of large atypical lymphocytes $(\mathbf{A}$, hematoxylin and eosin, $\times 600)$. Immunohistochemical staining revealed that the tumor cells were positive for CD3 (B, $\times 600)$ and CD30 (C, $\times 600)$. The patient received eight cycles of cyclophosphamide, doxorubicin, vincristine, and prednisolone $(\mathrm{CHOP})$ and achieved complete remission. Six months after the completion of CHOP chemotherapy, the first relapse was confirmed and the patient joined the Phase I study of oral forodesine. ${ }^{35}$ After 4 years of forodesine administration ( $100 \mathrm{mg}$, once daily), the patient experienced epigastric pain. Endoscopic examination revealed gastric ulcer lesions and a biopsy demonstrated the diffuse growth of large atypical lymphocytes ( $\mathbf{D}$, hematoxylin and eosin, $\times 400)$. Immunohistochemical staining revealed that the tumor cells were positive for CD20 (E, ×400). EBV early RNA I (EBERI) expression was detected in tumor cells by in situ hybridization $(\mathbf{F}, \times 400)$. The patient was diagnosed with EBV-positive DLBCL. The patient received cyclophosphamide, vincristine, procarbazine, and prednisolone (C-MOPP) in combination with rituximab, and subsequently achieved complete remission. 
two patients with PTCL-NOS) developed diffuse large B-cell lymphoma (DLBCL). Four of the five patients had EpsteinBarr virus (EBV)-positive DLBCL, which suggested that durable severe lymphocytopenia might be associated with the development of these secondary lymphomas. For example, the histopathological findings of EBV-positive DLBCL that developed during the administration of forodesine (not in this trial, but in our institution) are shown in Figure 3.

Based on the results of this pivotal study, oral forodesine was approved for the treatment of relapsed PTCLs in Japan in March 2017. Although this study met the primary end point, careful consideration is required in the application of this evidence into daily clinical practice, because: 1) the threshold response rate of $10 \%$ appears too low considering the efficacy of recently approved agents for T-cell lymphomas; 2) the study did not include refractory patients; and 3 ) the incidence of secondary EBV-positive DLBCL $(10 \%, 5$ out of 48 patients) is relatively high.

\section{Conclusion and future perspectives}

PNP inhibition has been expected to be a novel treatment option for the treatment of T-cell lymphomas for many years; forodesine finally achieved its first approval for relapsed/ refractory PTCL in Japan. Oral forodesine (300 mg BID) appeared to show better efficacy than that observed in lower dose previous trials of forodesine for PTCL and CTCL. In general, the toxicity of forodesine is manageable, and the oral formulation is more convenient than other novel intravenous agents approved for T-cell lymphomas. However, it is necessary to carefully manage opportunistic infections and secondary lymphomas possibly associated with durable lymphocytopenia.

Forodesine may contribute as one of the reasonable options for the treatment of relapsed T-cell lymphomas that have unmet medical needs. Although the ORR was not very high, some patients with T-cell lymphomas who received forodesine displayed favorable responses with long response durations. Further investigations to find the predictive markers of forodesine are warranted, as they may identify the patients who will receive maximum benefit from this novel oral agent.

\section{Acknowledgment}

This work was partially supported by the National Cancer Center Research and Development Fund (26-A-4, 29-A-3).

\section{Disclosure}

DM had received honoraria from Takeda, Janssen, and Eisai and research funding from Dai-ichi Sankyo, Chugai,
Kyowa Hakko Kirin, Ono, Celgene, Janssen, GSK, Eisai, Mundipharma, Takeda, AbbVie, MSD, Sanofi, Pfizer, Otsuka, Novartis, Solasia, and Zenyaku. KI has received research funding from Celgene, Daiichi Sankyo, Eisai, HUYA Bioscience International, Mundipharma, Solasia, and Takeda; consultancy from Celgene; and honararia from Eisai, Kyowa Hakko Kirin, and Takeda. KT has received research funding from Eisai, Mundipharma, Celgene, Solasia Pharma, Kyowa Hakko Kirin, and HUYA Bioscience International. The authors report no other conflicts of interest in this work.

\section{References}

1. Swerdlow SH, Campo E, Pileri SA, et al. The 2016 revision of the World Health Organization classification of lymphoid neoplasms. Blood. 2016;127:2375-2390.

2. Vose J, Armitage J, Weisenburger D; International T-Cell Lymphoma Project. International peripheral T-cell and natural killer/T-cell lymphoma study: pathology findings and clinical outcomes. J Clin Oncol. 2008;26:4124-4130.

3. Makita S, Tobinai K. Disease oriented treatment of T-cell lymphoma. Hematol Oncol. 2017;35:54-59.

4. Makita S, Tobinai K. Clinical features and current optimal management of natural killer/T-cell lymphoma. Hematol Oncol Clin North Am. 2017;31:239-253.

5. Reimer P, Rüdiger T, Geissinger E, et al. Autologous stem-cell transplantation as first-line therapy in peripheral T-cell lymphomas: results of a prospective multicenter study. J Clin Oncol. 2009;27:106-113.

6. Kitahara H, Maruyama D, Maeshima AM, et al. Prognosis of patients with peripheral $\mathrm{T}$ cell lymphoma who achieve complete response after CHOP/CHOP-like chemotherapy without autologous stem cell transplantation as an initial treatment. Ann Hematol. 2017;96:411-420.

7. Mak V, Hamm J, Chhanabhai M, et al. Survival of patients with peripheral T-cell lymphoma after first relapse or progression: spectrum of disease and rare long-term survivors. J Clin Oncol. 2013;31:1970-1976.

8. O'Connor OA, Pro B, Pinter-Brown L, et al. Pralatrexate in patients with relapsed or refractory peripheral T-cell lymphoma: results from the pivotal PROPEL study. J Clin Oncol. 2011;29:1182-1189.

9. Piekarz RL, Frye R, Turner M, et al. Phase II multi-institutional trial of the histone deacetylase inhibitor romidepsin as monotherapy for patients with cutaneous T-cell lymphoma. J Clin Oncol. 2009;27: 5410-5417.

10. Whittaker SJ, Demierre MF, Kim EJ, et al. Final results from a multicenter, international, pivotal study of romidepsin in refractory cutaneous T-cell lymphoma. J Clin Oncol. 2010;28:4485-4491.

11. Coiffier B, Pro B, Prince HM, et al. Romidepsin for the treatment of relapsed/refractory peripheral T-cell lymphoma: pivotal study update demonstrates durable responses. J Hematol Oncol. 2014;7:11.

12. Maruyama D, Tobinai K, Ogura M, et al. Romidepsin in Japanese patients with relapsed or refractory peripheral T-cell lymphoma: a phase I/II and pharmacokinetics study. Int J Hematol. 2017;106:655-665.

13. Pro B, Advani R, Brice P, et al. Brentuximab vedotin (SGN-35) in patients with relapsed or refractory systemic anaplastic large-cell lymphoma: results of a phase II study. J Clin Oncol. 2012;30:2190-2196.

14. Horwitz SM, Advani RH, Bartlett NL, et al. Objective responses in relapsed T-cell lymphomas with single-agent brentuximab vedotin. Blood. 2014;123:3095-3100.

15. Prince HM, Kim YH, Horwitz SM, et al. Brentuximab vedotin or physician's choice in CD30-positive cutaneous T-cell lymphoma (ALCANZA): an international, open-label, randomised, phase 3, multicentre trial. Lancet. 2017;390:555-566.

16. Shi Y, Dong M, Hong X, et al. Results from a multicenter, openlabel, pivotal phase II study of chidamide in relapsed or refractory peripheral T-cell lymphoma. Ann Oncol. 2015;26:1766-1771. 
17. Makita S, Tobinai K. Mogamulizumab for the treatment of T-cell lymphoma. Expert Opin Biol Ther. 2017;17:1145-1153.

18. Ogura M, Ishida T, Hatake K, et al. Multicenter phase II study of mogamulizumab (KW-0761), a defucosylated anti-cc chemokine receptor 4 antibody, in patients with relapsed peripheral T-cell lymphoma and cutaneous T-cell lymphoma. J Clin Oncol. 2014;32:1157-1163.

19. Zinzani PL, Karlin L, Radford J, et al. European phase II study of mogamulizumab, an anti-CCR4 monoclonal antibody, in relapsed/refractory peripheral T-cell lymphoma. Haematologica. 2016;101:e407-e410.

20. Duvic M, Pinter-Brown LC, Foss FM, et al. Phase 1/2 study of mogamulizumab, a defucosylated anti-CCR4 antibody, in previously treated patients with cutaneous T-cell lymphoma. Blood. 2015;125: 1883-1889.

21. Mann BS, Johnson JR, He K, et al. Vorinostat for treatment of cutaneous manifestations of advanced primary cutaneous T-cell lymphoma. Clin Cancer Res. 2007;13:2318-2322.

22. O'Connor OA, Horwitz S, Masszi T, et al. Belinostat in patients with relapsed or refractory peripheral T-cell lymphoma: results of the pivotal phase II BELIEF (CLN-19) study. J Clin Oncol. 2015;33: 2492-2499.

23. Kim BK, Cha S, Parks RE Jr. Purine nucleoside phosphorylase from human erythrocytes. I. Purification and properties. J Biol Chem. 1968; 243:1763-1770.

24. Giblett ER, Ammann AJ, Wara DW, Sandman R, Diamond LK. Nucleoside-phosphorylase deficiency in a child with severely defective T-cell immunity and normal B-cell immunity. Lancet. 1975;1: 1010-1013.

25. Carson DA, Kaye J, Seegmiller JE. Lymphospecific toxicity in adenosine deaminase deficiency and purine nucleoside phosphorylase deficiency: possible role of nucleoside kinase(s). Proc Natl Acad Sci US A. 1977;74:5677-5681.

26. Carson DA, Kaye J, Matsumoto S, Seegmiller JE, Thompson L. Biochemical basis for the enhanced toxicity of deoxyribonucleosides toward malignant human T cell lines. Proc Natl Acad Sci U S A. 1979; 76:2430-2433.

27. Kazmers IS, Mitchell BS, Dadonna PE, et al. Inhibition of purine nucleoside phosphorylase by 8 -aminoguanosine: selective toxicity for T lymphoblasts. Science. 1981;214:1137-1139.

28. Gilbertsen RB, Josyula U, Sircar JC, et al. Comparative in vitro and in vivo activities of two 9-deazaguanine analog inhibitors of purine nucleoside phosphorylase, CI-972 and PD 141955. Biochem Pharmacol. 1992;44:996-999.

29. Viegas TX, Omura GA, Stoltz RR, Kisicki J. Pharmacokinetics and pharmacodynamics of peldesine (BCX-34), a purine nucleoside phosphorylase inhibitor, following single and multiple oral doses in healthy volunteers. J Clin Pharmacol. 2000;40:410-420.

30. Morris PE Jr, Elliott AJ, Walton SP, Williams CH, Montgomery JA. Synthesis and biological activity of a novel class of purine nucleoside phosphorylase inhibitors. Nucleosides Nucleotides Nucleic Acids. 2000; 19:379-404
31. Conry RM, Bantia S, Turner HS, et al. Effects of a novel purine nucleoside phosphorylase inhibitor, BCX-34, on activation and proliferation of normal human lymphoid cells. Immunopharmacology. 1998;40:1-9.

32. Bantia S, Miller PJ, Parker CD, et al. Purine nucleoside phosphorylase inhibitor BCX-1777 (Immucillin-H) - a novel potent and orally active immunosuppressive agent. Int Immunopharmacol. 2001;1: 1199-1210.

33. Kilpatrick JM, Morris PE, Serota DG Jr, et al. Intravenous and oral pharmacokinetic study of BCX-1777, a novel purine nucleoside phosphorylase transition-state inhibitor. In vivo effects on blood 2'-deoxyguanosine in primates. Int Immunopharmacol. 2003;3:541-548.

34. Kicska GA, Long L, Hörig $\mathrm{H}$, et al. Immucillin $\mathrm{H}$, a powerful transitionstate analog inhibitor of purine nucleoside phosphorylase, selectively inhibits human T lymphocytes. Proc Natl Acad Sci U S A. 2001;98: 4593-4598.

35. Al-Kali A, Gandhi V, Ayoubi M, Keating M, Ravandi F. Forodesine: review of preclinical and clinical data. Future Oncol. 2010;6: 1211-1217.

36. Gandhi V, Kilpatrick JM, Plunkett W, et al. A proof-of-principle pharmacokinetic, pharmacodynamic, and clinical study with purine nucleoside phosphorylase inhibitor immucillin-H (BCX-1777, forodesine). Blood. 2005;106:4253-4260.

37. Furman RR, Gore L, Ravandi F, Hoelzer D. Forodesine IV (Bcx-1777) is clinically active in relapsed/refractory T-cell leukemia: results of a phase II study (interim report). Blood. 2006;108:1851 [Abstract].

38. Duvic M, Forero-Torres A, Foss F, Olsen E, Kim Y. Response to oral forodesine in refractory cutaneous T-cell lymphoma: interim results of a phase I/II study. Blood. 2007;110:122 [Abstract].

39. Dummer R, Duvic M, Scarisbrick J, et al. Final results of a multicenter phase II study of the purine nucleoside phosphorylase (PNP) inhibitor forodesine in patients with advanced cutaneous T-cell lymphomas (CTCL) (Mycosis fungoides and Sézary syndrome). Ann Oncol. 2014; 25:1807-1812.

40. Ogura M, Tsukasaki K, Nagai H, et al. Phase I study of BCX1777 (forodesine) in patients with relapsed or refractory peripheral $\mathrm{T} /$ natural killer-cell malignancies. Cancer Sci. 2012;103:1290-1295.

41. Tsukasaki K, Tobinai K, Uchida T, et al. Phase $1 / 2$ study of forodesine in patients with relapsed peripheral T-cell lymphoma (PTCL). J Clin Oncol. 2016;34:7542 [Abstract].

42. Shibayama H, Tobinai K, Tsukasaki K, et al. Updated report of a phase I/II multicenter study of forodesine, a purine nucleoside phosphorylase inhibitor, in Japanese patients with relapsed peripheral T-cell lymphoma. In: ASH 59th Annual Meeting and Exposition; December 9-12, 2017; Atlanta, GA. Abstract\#4075.

43. Cheson BD, Pfistner B, Juweid ME, et al. Revised response criteria for malignant lymphoma, J Clin Oncol. 2007;25:579-586.
OncoTargets and Therapy

\section{Publish your work in this journal}

OncoTargets and Therapy is an international, peer-reviewed, open access journal focusing on the pathological basis of all cancers, potential targets for therapy and treatment protocols employed to improve the management of cancer patients. The journal also focuses on the impact of management programs and new therapeutic agents and protocols on

\section{Dovepress}

patient perspectives such as quality of life, adherence and satisfaction. The manuscript management system is completely online and includes a very quick and fair peer-review system, which is all easy to use. Visit http://www.dovepress.com/testimonials.php to read real quotes from published authors. 